\title{
Aglomeração industrial, governança e meio ambiente: conceitos e premissas da abordagem do desenvolvimento territorial sustentável
}

\section{Industrial Clustering, Governance, and Environment: Contributions, Concepts, and Assumptions of the Sustainable Territorial Development Approach}

\author{
Elaine Cristina de Oliveira MENEZES* \\ Paulo Henrique Freire VIEIRA**
}

\begin{abstract}
RESUMO
$\mathrm{O}$ resgate atento da literatura sobre o conceito de ecodesenvolvimento desempenhou um papel de indiscutível relevância para compreender como as dinâmicas produtivas territoriais impactam sobre o meio ambiente. Observa-se que os estilos de desenvolvimento contemporâneos não vêm favorecendo a internalização da problemática socioambiental nas práticas usuais de planejamento e gestão. É no âmbito desse escopo que se situa a discussão proposta neste estudo, cujo objetivo é analisar quais as contribuições das teorias de desenvolvimento territorial e das discussões sobre a sustentabilidade socioambiental para a abordagem do desenvolvimento territorial sustentável. Os aspectos metodológicos adotados neste estudo estão pautados numa abordagem predominantemente qualitativa, baseada na revisão seletiva da literatura pertinente ao tema. Fundamenta-se na pesquisa bibliográfica, obtida de fontes secundárias, de obras de renome nacional e internacional sobre as dinâmicas produtivas territoriais, governança e sustentabilidade socioambiental. No âmbito do resgate conceitual que norteou a construção deste ensaio, tem-se o desenvolvimento territorial sustentável como um processo em construção, tendo como ponto de partida a problemática da degradação socioambiental e sua relação com estratégias de desenvolvimento de longo prazo. No seio desse conceito-chave destaca-se, por um lado, a contribuição da abordagem territorial que trouxe inovações no campo socioeconômico e sociopolítico; por outro lado, as contribuições das discussões sobre sustentabilidade, fundamentadas no ecodesenvolvimento, também resgatam elementos imprescindíveis para a gestão territorial e socioambiental. Conclui-se pela necessidade de estudos empíricos que integrem essa problemática e que possam fazer avançar esse novo enfoque de planejamento e gestão: o desenvolvimento territorial sustentável.
\end{abstract}

Palavras-chave: desenvolvimento territorial sustentável; aglomeração industrial; governança.

\footnotetext{
* Doutora em Sociologia Política (UFSC). Pós-Doutoranda do Programa de Pós-Graduação em Administração da Universidade Federal de Santa Catarina (UFSC). Email: eoliveira.menezes@gmail.com

** Doutor em Ciência Política (Ludwig-Maximilians Universität München - Alemanha). Professor titular do Departamento de Sociologia e Ciência Política da Universidade Federal de Santa Catarina (UFSC) e pesquisador do CNPq. Email: vieira.p@cfh.ufsc.br
} 


\begin{abstract}
The acute rescue of the literature on the concept of eco-development performed a role of unquestioned relevance to understand how the territorial productive dynamics have some impact on the environment. It is observed that the styles of contemporary development are not favoring the internalization of the socio-environmental problem in the usual practices of planning and management. The discussion proposed in this study is situated in this scope, whose objective is to analyze the contributions of the territorial development theories and the discussions on the socio-environmental sustainability to approach the sustainable territorial development. The methodological aspects adopted in this study are oriented in a predominantly qualitative approach, based on a selective review of the relevant literature on the subject. The study was based on the bibliographic research obtained from secondary sources, in national and international studies on the territorial productive dynamics, governance and environmental sustainability. In the conceptual scope that guided this study the sustainable territorial development is considered as an ongoing process whose starting point is the socio-environmental degradation issue, and its relation to the strategies for long-term development. Within this concept the contribution of the territorial approach that has brought innovations to the socioeconomic and socio-political fields stands out. On the other hand, the contributions from the discussions on sustainability based on eco-development also rescue the essential elements for territorial and environmental management. We conclude that there are needs for empirical studies that integrate this issue and that can take this new management and planning approach further: the sustainable territorial development.
\end{abstract}

Key-words: sustainable territorial development; industrial clustering; governance.

\section{Introdução}

Durante muitos anos, os termos "crescimento econômico" e "desenvolvimento econômico" apresentaram significados semelhantes, ora sendo definidos como aumento da produção de bens e serviços em escala global, ora como melhoria progressiva da qualidade de vida. Essa distinção inscreve-se, no entanto, em um debate antigo e vasto no campo da economia do desenvolvimento. Nesse contexto, a partir da segunda metade do século passado observa-se a ascensão de inúmeras vertentes teóricas preocupadas em explicar o fenômeno do desenvolvimento, principalmente no âmbito das economias denominadas, por alguns autores na atualidade, periferia (ARRIGHI, 1998; WALLERSTEIN, 2002). Os três grandes paradigmas, compostos por um conjunto de teorias que buscaram explicar esse fenômeno no século passado, foram recentemente sintetizados no trabalho de Andion (2007).

O primeiro deles corresponde ao chamado paradigma desenvolvimentista, que se impôs durante o período de 1940 a 1970, inspirado no modelo fordista. Seus adeptos apoiavam suas reflexões em dois pilares: a ação centralizadora e polarizadora do Estado, vista como promotora dos direitos sociais básicos, e o sistema de livre mercado, distribuidor das riquezas geradas pelos sistemas produtivos. Trata-se da ideia do desenvolvimento como processo de crescimento contínuo e cumulativo. O segundo, denominado paradigma heterodoxo - que acompanha a conjuntura das décadas de 1960 e 1970 -, fundamenta-se na utilização dos conceitos centrais da teoria marxista, mas foi adaptado por várias correntes de pensamento: neomarxistas, estruturalistas e dependentistas. Essas correntes avaliavam as inter-relações entre desenvolvimento e subdesenvolvimento, situando o subdesenvolvimento como o resultado histórico de relações de dominação nos cenários internacional e nacional. Por fim, o paradigma neoliberal, que emergiu no transcurso dos anos 1980, resgata as ideias dos clássicos da teoria econômica, relacionadas à regulação no âmbito do mercado operando de forma supostamente livre, e tem sido predominante no contexto atual de globalização assimétrica.

A reconstrução desse debate demonstra que as transformações observadas na estrutura econômica atual nas dinâmicas territoriais e socioambientais têm sido progressivamente absorvidas pelos teóricos do desenvolvimento. Muitas questões sobre a problemática territorial e socioambiental emergiram já no século passado, demonstrando grandes inovações que suscitavam nesse campo de estudo. É preciso destacar, de um lado, a crise do fordismo e as inúmeras experiências territorializadas como elementos 
que colocaram em pauta uma nova configuração do sistema econômico global (PIORE; SABEL, 1984; BENKO; LIPIETZ, 2000). Essas reflexões contribuíram decisivamente para o reenquadramento analítico do fenômeno do desenvolvimento. De outro lado, também se observa que, desde a década de 1960, há incorporação de evidências de uma crise socioambiental de escopo planetário e os efeitos perversos da visão utilitarista e economicista da problemática do desenvolvimento (MEADOWS et. al., 1978).

Embora se reconheça que muitos estudos sobre dinâmicas territoriais de desenvolvimento estejam situados em campos teóricos distintos, a integração da problemática ecológica tem sido formatada em nome do enfoque de desenvolvimento territorial sustentável - DTS (VIEIRA, 2006; VIEIRA; CAZELLA, 2004). Conforme Vieira e Cazella (2004), na redescoberta da dimensão territorial do desenvolvimento, nos últimos anos, o resgate atento da literatura sobre o conceito de ecodesenvolvimento desempenhou um papel de indiscutível relevância. De maneira geral, evidencia-se que os estilos de desenvolvimento contemporâneos não vêm favorecendo a internalização da problemática socioambiental nas práticas usuais de planejamento e gestão.

Dentro desse quadro analítico, o desenvolvimento territorial sustentável se coloca como em processo de elaboração, tendo como ponto de partida a problemática da degradação socioambiental e sua relação com estratégias de desenvolvimento de longo prazo, mobilizando um conjunto interdependente de critérios de avaliação normativa: (1) prioridade ao alcance de finalidades sociais, tais como satisfação de necessidades básicas - materiais e intangíveis - e promoção da equidade; (2) prudência ecológica; (3) autonomia (ou self-reliance); e (4) redefinição do conceito de eficiência econômica com base numa ecologia humana embasada no novo paradigma sistêmico.

É no âmbito desse escopo que se situa a discussão proposta neste artigo, cujo objetivo é analisar quais as contribuições das teorias de desenvolvimento territorial, especialmente aquelas relativas aos sistemas produtivos locais, às discussões sobre a sustentabilidade socioambiental e aos impactos dos sistemas produtivos sobre o meio ambiente para o aporte do desenvolvimento territorial sustentável. É preciso atentar, também, para o fato de que a abordagem do desenvolvimento territorial, resgatada no Brasil principalmente por meio da mobilização do conceito de arranjo produtivo local e governança, ainda tem incorporado de maneira marginal a problemática socioambiental. É incon- testável, porém, que há inovações importantes a serem consideradas e que podem contribuir para se pensar a economia no contexto do desenvolvimento, auxiliando na tomada de consciência da problemática socioambiental atual.

Quanto aos aspectos metodológicos adotados para construção deste artigo, estes estão pautados numa abordagem predominantemente qualitativa, baseada na revisão seletiva da literatura pertinente ao tema. A pesquisa é do tipo exploratório, cuja finalidade foi de buscar, no conjunto da abordagem territorial e do ecodesenvolvimento, aprofundar algumas das suas linhas de argumentação e promover a intersecção de elementos conceituais complementares. Este estudo fundamentou-se, para tanto, na pesquisa bibliográfica, sendo o acesso à coleta de dados por meio de fontes secundárias, de obras de renome nacional e internacional.

O presente artigo foi estruturado, primeiramente, com a apresentação das modalidades de aglomerações industriais identificadas no espectro das várias teorias do desenvolvimento territorial em circulação atualmente. Num segundo momento, incorporam-se as diversas abordagens sobre sistemas de governança, suas tipologias e especificidades na busca de compreensão das dinâmicas territoriais de desenvolvimento, com o intuito de aproximar ainda mais as problemáticas dos arranjos produtivos locais com a questão da sustentabilidade. Finalmente, abordam-se as análises que focalizam a temática dos impactos socioambientais dos sistemas produtivos e as contribuições da concepção de sustentabilidade e, por fim, busca-se integrar as reflexões dos diferentes conceitos apresentados nas considerações finais, demonstrando a fertilidade da abordagem do DTS como uma teoria normativa e sistêmica para replicar-se em estudos empíricos.

\section{O desenvolvimento territorial sustentável em debate: elementos e conceitos que integram essa nova abordagem}

A construção do enfoque do desenvolvimento territorial sustentável faz parte de um processo de tomada de consciência acerca da problemática socioambiental nos anos 1960 e 1970. A crise socioambiental expõe os limites relacionados ao modelo de desenvolvimento hegemônico e também se manifesta como crise do conhecimento. Os especialistas acostumados a lidar com o conhecimento parcial passam a encarar essa problemática como multidimensional, exigindo um tratamento interdisciplinar (VIEIRA, 2005). 
Dessa forma, verifica-se um processo de reconceituação do desenvolvimento a partir da contribuição do enfoque sobre sustentabilidade socioambiental e territorialidade.

Ao tratar-se dessa nova abordagem, considera-se necessário resgatar seus pontos referenciais e, dentre eles, tem-se Maurice Strong que, em 1973, coloca em cena, pela primeira vez, o termo ecodesenvolvimento como um estilo alternativo de desenvolvimento para o Terceiro Mundo. Ignacy Sachs, em 1974, retoma o conceito, ampliando seu significado e apontando para a importância de se tratar das causas da problemática socioambiental e não dos seus efeitos. Em sua dimensão normativa, enfatiza a prioridade das finalidades sociais; a prudência ecológica; a autoconfiança, a autodeterminação e a participação no planejamento; e o reenquadramento da economia nesse contexto (SACHS, 1986; VIEIRA, 2005).

O termo ecodesenvolvimento foi, no entanto, logo abandonado por ser considerado radical demais. Atualmente, há um consenso quanto à utilização do termo desenvolvimento sustentável. O termo é associado ao Relatório Nosso Futuro Comum, mais conhecido como Relatório Brundtland, documento elaborado pela Comissão Mundial sobre o Meio Ambiente e Desenvolvimento no ano de 1987. Sua ênfase consiste na realização das necessidades da geração atual sem prejudicar as gerações futuras. Muitos consideram o conceito pouco definido, podendo justificar muitos discursos e práticas pouco sustentáveis. Vale lembrar, todavia, que, para os que inscrevem suas reflexões no ecodesenvolvimento, o desenvolvimento sustentável é uma oportunidade para consolidar trabalhos antigos e abrir novos espaços para a pesquisa.

É preciso destacar, também, que num período mais ou menos coincidente ao surgimento do termo ecodesenvolvimento emerge outro conceito-chave: o de território. Tal conceito, na atualidade, é bastante polissêmico e complexo. A noção de território, entretanto, é compreendida a partir da premissa de que esse está inserido no espaço, que, por sua vez, relaciona um conjunto de elementos, tanto naturais quanto sociais. Por meio da combinação dos agentes e processos físicos e humanos, conduz-se a utilização desse espaço através da sua apropriação e de seu controle. $\mathrm{O}$ conceito de território tem, portanto, não só um componente físico, mas também social e político. E é no âmbito desses estudos sobre a questão da territorialidade que emerge o conceito de desenvolvimento territorial.

Neste artigo, busca-se enfatizar a fertilidade dos estudos sobre as aglomerações industriais e dos sistemas de governança tributários dessa abordagem territorial do desenvolvimento. Foram as discussões das abordagens territoriais que, definitivamente, recuperaram o conceito de território e o trouxeram para a ordem do dia. Assim, o que se pretende destacar é a importância dessa concepção para compreender as dinâmicas socioambientais atuais. Em função das discussões atuais remeterem ao conceito de globalização e mundialização, não se pode esquecer que as questões territoriais são extremamente importantes para entender o global, assim como as questões do processo de globalização são relevantes para compreender as dinâmicas locais.

O ponto de partida para o resgate teórico do desenvolvimento territorial sustentável está na recuperação das dimensões socioeconômcica, sociopolítica e socioambiental do desenvolvimento (VIEIRA; CAZELLA, 2004). É preciso atentar para o fato de que tanto as abordagens territoriais no planejamento do desenvolvimento quanto os estudos acadêmicos no campo ecológico-humano contemplam uma grande diversidade de perspectivas teóricas e metodológicas. A intenção aqui é, contudo, a de resgatar aquelas que se consideram mais relevantes para o enquadramento analítico do desenvolvimento territorial sustentável e suas implicações para os sistemas produtivos. Nesse sentido, a seção seguinte é um esforço de síntese das principais correntes relativas às aglomerações industriais fundamentadas na abordagem territorial do desenvolvimento, com o intuito de apresentar aquelas mais férteis para a discussão sobre DTS.

\subsection{Desenvolvimento territorial: dos distritos industriais aos arranjos produtivos locais}

É incontestável que, desde o início dos anos 1970, assiste-se a uma nova forma de distribuição das atividades produtivas no espaço. Essas transformações encontram-se no seio da crise do modelo fordista de produção, marcada pelas dificuldades de adaptação das pequenas empresas ao contexto dos mercados. Nesse período, surgiram inúmeras correntes que podem ser agrupadas em três grandes abordagens: distritos industriais, ambiente inovador e clusters. Todas essas correntes promoveram inovações no campo teórico da economia e contribuíram para o debate sobre as mudanças em curso desde então. Em fins da década de 1990, integrou-se a essas correntes teóricas a corrente brasileira, que congrega tais perspectivas em um novo conceito: o de arranjos produtivos locais, formalizado por uma rede de 
pesquisa interdisciplinar, sediada no Instituto de Economia da Universidade Federal do Rio de Janeiro.

É preciso atentar para o fato de que os aprofundamentos teóricos sobre o tema partem da ideia de reorganização industrial vista com um misto de concorrência-cooperação no contexto das pequenas e médias empresas - no sentido da definição de distrito industrial. Tal conceito foi utilizado pela primeira vez em fins do século XIX, a partir de um padrão de organização existente na Inglaterra neste mesmo século, estudado por Alfred Marshall (BENKO, 1996). Para este autor, assim como a reunião dos artesãos na fábrica do século XIX, as aglomerações representam a primeira condição a ser levada em conta na busca de compreender as transformações do mercado capitalista.

Embora a reflexão de Alfred Marshall tenha iniciado esse debate, para Courlet e Soulage (1994) ela se exprimiu essencialmente em termos de eficiência, considerando que as principais características desse tipo de dinâmica produtiva seriam: alto grau de especialização e forte divisão do trabalho; acesso à mão de obra qualificada; existência de fornecedores locais de insumos e bens intermediários; sistemas de comercialização e de troca de informações entre os agentes. Tendo por base os autores supramencionados, nota-se, entretanto, que esses fatores não explicam o ponto essencial das vantagens de uma configuração territorial concentrada. Entre as economias disponíveis, em um distrito industrial, devem ser levadas em conta as relações com a educação e a formação especializada - o know how -, bem como os benefícios das relações de reciprocidade e confiança.

É preciso, contudo, ressaltar o fato de que muitas regiões manifestaram esse tipo de dinâmica socioeconômica após o surgimento do conceito de distrito industrial marshalliano. Putnam (2002) acredita que o próprio incentivo à reestruturação industrial da Europa, após a Segunda Guerra Mundial, trouxe benefícios à formação desse tipo de estrutura produtiva. O essencial dessa noção reside, efetivamente, na concepção de uma entidade produtiva ancorada num da- do espaço geográfico. Assim, a aposta do desenvolvimento territorial coloca em evidência uma dinâmica que valoriza a eficácia das relações não exclusivamente mercantis entre os homens e as suas riquezas, sejam elas culturais, sejam econômicas ou mesmo ambientais (PECQUEUR, 2004).

Para aprofundar esse debate, resgatam-se nesta seção as principais características das três correntes da abordagem territorial referenciadas anteriormente e também a perspectiva dos arranjos produtivos locais. As diferenças existentes entre elas são tênues, em virtude de emergirem na mesma época e de serem concorrentes quanto a seus pressupostos básicos (AMARAL FILHO, 2007; LEMOS, 2003). A primeira delas, a dos distritos industriais, tem, na década de 1980, em Becattini ${ }^{1}$, Brusco, Piore e Sabel ${ }^{2}$, entre outros, a contribuição com o resgate do conceito marshalliano de distrito industrial, em função do aparecimento de inovações na Terceira Itália, após a Segunda Guerra Mundial. As primeiras experiências observadas foram as ocorridas entre o eixo Milão-Turin-Gênova e a região Sul, marcada pela pobreza. Pequenas empresas familiares, com características de propriedades rurais, configuraram um novo padrão de organização industrial, pautado na solidariedade e na cooperação. O que mais despertou o interesse dos pesquisadores, principalmente dos sociólogos e economistas, diante da dinâmica industrial dessa região, foram os resultados positivos alcançados na balança do comércio exterior (COCCO; GALVÃO; SILVA, 1999).

Os primeiros estudos realizados na Terceira Itália sobre o desenvolvimento endógeno foram creditados a Becattini (1989). Essas experiências demonstraram, por meio da concentração de Micro e Pequenas Empresas MPEs, baseadas em atividades tradicionais, com forte divisão social do trabalho e cooperação, a possibilidade de reversão do quadro de crise vigente no pós-guerra. O que marca, portanto, essa corrente teórica é a ênfase concedida à formação de um tecido social cooperativo, pautado em relações de reciprocidade e de confiança ${ }^{3}$, em busca de superação da crise desses territórios (BECATTINI, 1989; 1999).

\footnotetext{
${ }^{1}$ Ver detalhes em BECATTINI, G. Les districts industriels. In: MARUANI, M. et al. La flexibilité en Italie. Paris: MIRE, Syros/Alternative, 1989.

${ }^{2}$ Ver detalhes em PIORE, Michael J.; SABEL, Charles F. The second industrial divide: possibilities for prosperity. New York: Basic Books, 1984.

${ }^{3}$ Essa eficiência socioeconômica coletiva demonstra, mais intensamente por volta da década de 1970, como as mudanças institucionais formais e a passagem do Estado autoritário para a democracia puderam induzir transformações no comportamento político e também econômico do território italiano (PUTNAM, 2002). Este autor expõe que as identidades regionais e locais sempre foram fortes na Itália. Comprovando o enraizamento local existente na Itália, neste período verifica-se que, durante muitos anos, havia grande diversidade linguística, a ponto de apenas cerca de $10 \%$ dos italianos falarem o idioma nacional. Segundo Putnam (2002), esse fato reforça a grande integração das comunidades locais e a existência de uma identidade local, o que ilustra como a dinâmica social pode influenciar na estrutura econômica regional. A proliferação de significativo número de empresas de setores tradicionais, em regiões pouco desenvolvidas da Itália e de forma espontânea, demonstrou que, muitas vezes, mesmo com ausência de projetos políticos nacionais, a economia pode engendrar-se a partir de processos endógenos de desenvolvimento (BAGNASCO, 1999).
} 
Tais processos endógenos de desenvolvimento encontram, na especificidade dos fatores culturais, um terreno fértil para a multiplicação das pequenas empresas (BAGNASCO, 1999). Esses fatores culturais representavam uma reação à organização do trabalho na grande indústria; trabalho estandartizado, com baixo nível de qualificação e avesso ao cultivo de relações interpessoais. Deve-se destacar também, na linha de Amaral Filho (2007), que há uma profusão de correntes teóricas e que são inúmeras as filiações conceituais das dinâmicas econômicas dos distritos industriais. Todas elas, porém, tendem a enfatizar a contribuição do meio sociocultural para a consolidação de relações de cooperação, sendo algumas de suas principais vertentes a do sistema produtivo territorial, a da estrutura industrial local, a do ecossistema localizado e a do sistema industrial localizado.

A segunda grande vertente, por outro lado, relativa à noção de ambiente inovador, pode ser relacionada à rede de pesquisadores vinculada ao Grupo Europeu de Pesquisa sobre os Ambientes Inovadores - Associação Philippe Aydalot, tendo como principais representantes Philippe Aydalot, Denis Maillat e Olivier Crevoisier, entre outros (AMARAL FILHO, 2007; LEMOS, 2003; BENKO, 1996). Essa corrente tem como preocupação central oferecer elementos que contribuam para a sobrevivência dos distritos industriais e para que outras regiões possam conceber, com eficácia, projetos de desenvolvimento com perfil cada vez mais endógeno. Para tanto, seus adeptos conferem às inovações tecnológicas um papel determinante.

Segundo Amaral Filho (2007), os milieux innovateurs se constituem como o locus de processos de ajustamentos, de transformação e de evoluções permanentes. Tais processos são acionados por uma lógica de interação e por uma dinâmica de aprendizagem contínua. O ponto essencial reside no fato de as regiões perceberem e compreenderem as mudanças tecnológicas e mercadológicas, para assim reforçarem sua capacidade de resposta às mudanças, por meio da mobilização dos recursos, conhecimento, laços de cooperação e dinâmicas de aprendizagem institucional. Quanto a essa questão, Maillat (1995) postula que existem alternativas à crença na suposta subordinação do desenvolvimento de uma dada região à capacidade de atração de grandes empresas (ou de suas filiais).
Atualmente, o desenvolvimento regional com perfil endógeno dependeria, segundo o autor supramencionado, antes, de um reagrupamento territorial dos atores econômicos e da presença de recursos imateriais (formação e pesquisa). Dessa maneira, seriam desenvolvidas competências, know how e regras ajustadas às características locais. Postula-se, então, que a proximidade favorece a aprendizagem e a expressão da criatividade (MAILLAT, 1995). Um milieu inovativo, assim, pode ser definido como "[...] o local, ou a complexa rede de relações sociais em uma área geográfica limitada que intensifica a capacidade inovativa local através de processo de aprendizado sinérgico e coletivo" (CAMAGNI apud LEMOS, 2003, p. 45). Nesse sentido, essa corrente teórica alimenta-se de certos atributos dos enfoques schumpeterianos ${ }^{4}$, neoschumpeterianos e de outras vertentes que colocam as dinâmicas de promoção da inovação e da aprendizagem no centro das atenções.

Já a corrente vinculada às análises em termos de clusters resgata, também, o conceito marshalliano de distrito industrial. Segundo Amaral Filho (2007), o termo cluster, de origem anglo-saxã, denota agrupamento ou cacho. Trata-se aqui de um esforço de integração das perspectivas dos distritos industriais e dos milieux innovateurs. Refere-se a uma concentração, num território geográfico delimitado, de empresas interdependentes que se beneficiam das mesmas oportunidades na busca de enfrentamento de problemas compartilhados (ROSENFELD, 1996). Michael Porter ${ }^{5}$ foi o autor que obteve maior influência no desenvolvimento dessa corrente, recuperando as noções de polo de crescimento e indústria-motriz. A ideia seria transformar determinada indústria-chave em líder de mercado na região.

A noção de cluster aproxima-se, assim, da noção de produção flexível de grande porte muito mais do que da pequena produção flexível. Observa-se, a partir do enfoque baseado na noção de cluster, que existem semelhanças com as demais abordagens apresentadas. Nota-se, todavia, que os autores que se vinculam a essa vertente enfatizam a busca de vantagens competitivas. Embora essa corrente seja uma das mais difundidas no mundo atualmente, ela vincula-se muito mais ao mercado do que aos problemas relacionados à busca de ordenamento territorial.

Ao realizar um balanço dessas três vertentes teóricas - distrito industrial, millieux innovateurs e cluster -,

\footnotetext{
${ }^{4}$ Ver SCHUMPETER, J. The theory of economic development. Cambridge: Harvard University, 1934.

${ }^{5}$ Ver PORTER, M. Aglomerados e competição: novas agendas para empresas, governos e instituições. In: . Competição. Rio de Janeiro: Campus, 1999. Cap. 7.
} 
destaca-se o que há de comum entre os três enfoques, a saber: a proximidade e a localização, os atores envolvidos e as características geradas pelos sistemas produtivos. Há, porém, algumas diferenças nessas três abordagens, na opinião de Amaral Filho (2007). A abordagem dos milieux innovateurs difere daquela do distrito industrial. Enquanto a segunda privilegia a visão do bloco social, a primeira confere às inovações tecnológicas certa autonomia e um papel determinante no conjunto das empresas. A noção de cluster, por sua vez, pelo fato de constituir uma síntese das abordagens dos distritos industriais e milieux innovateurs, estaria mais próxima da concepção de um modelo (normativo), enquanto as outras duas apresentam um perfil de construção mais intuitiva. Os exemplos mais promissores desse tipo de dinâmica, segundo Benko (1996), são os casos típicos das aglomerações tecnológicas do Silicon Valley, das aglomerações artesanais ou de MPEs vinculadas ao modelo proposto pela Terceira Itália e das aglomerações financeiras e de serviços das grandes metrópoles.

Apesar de essas abordagens terem proporcionado uma melhor compreensão de experiências promissoras de desenvolvimento territorial, ou mesmo local, elas retrataram a realidade de regiões específicas, não devendo ser tomadas como modelo ou fórmulas do "bom desenvolvimento". O mimetismo, nesse caso, deve ser criticado. Se parece óbvio que é possível aprender com as inúmeras experiências em curso, deve-se reconhecer, entretanto, os limites de aplicabilidade em outros territórios que não compartilham as mesmas especificidades sociais, culturais, políticas, econômicas e mesmo ambientais. Com o intuito de tornar compatível a países em desenvolvimento, como o Brasil, os conceitos que foram aplicados à realidade dos países desenvolvidos, pesquisadores como Lastres e Cassiolato (2003) organizaram, por isso, a Rede de Pesquisa em Arranjos e Sistemas Produtivos e Inovativos Locais (RedeSist). Optando por uma nomenclatura mais compatível com a realidade brasileira, a RedeSist concebe e define um agrupamento de empresas, denominado arranjo produtivo local, como um conjunto de agentes econômicos, políticos e sociais disseminados num dado território e que desenvolvem atividades correlatas, permeadas por vínculos de produção, interação, cooperação e aprendizagem - mesmo que incipientes (LASTRES; CASSIOLATO, 2003; LEMOS, 2003).

Para essa rede de pesquisadores, um sistema produtivo local representa o estágio mais avançado de desenvolvimento de uma dada aglomeração industrial. Se um sistema produtivo é o estágio mais avançado de evolução, um arranjo produtivo local seria, então, organizado por qualquer forma de aglomeração produtiva territorializada "[...] cuja dinâmica e desempenho não apresentam elementos suficientes de interação e que, por meio de articulação de seus atores e da aplicação de instrumentos adequados, possam construir e reforçar processos de aprendizado, cooperação e inovação visando se tornar sistemas produtivos e inovativos locais" (LEMOS, 2003, p. 81). Essa proposta facilita a adoção da análise territorial, especialmente em regiões (países) cujas aglomerações industriais encontram-se, ainda, em estágios intermediários de organização e em função de poderem ser alvo de políticas públicas de fomento. Portanto, além de facilitar a análise das organizações produtivas da realidade brasileira, Lastres e Cassiolato (2003) indicam outros pontos, visando orientar a formulação de políticas de fomento de arranjos produtivos e inovativos locais. Com efeito, é preciso reconhecer a complexidade que permeia a noção prática desse tipo de dinâmica produtiva e, consequentemente, o desenvolvimento de políticas de fomento.

Além disso, embora se reconheça a fertilidade da abordagem territorial para as dinâmicas de desenvolvimento, verifica-se que os inúmeros trabalhos realizados à luz desse enfoque têm demonstrado que a dimensão socioeconômica ainda é predominante. Decorre daí a necessidade de se reconhecer os seus limites, buscando integrar aos estudos sobre o tema outros elementos que não, unicamente, a eficiência microempresarial e que reforcem a adoção de uma perspectiva ecológico-humana nas análises do desenvolvimento territorial. Embora a preocupação com a sustentabilidade seja ainda marginal nesses estudos, nas próximas seções serão introduzidos alguns subsídios que apontam na direção de uma incorporação mais sistemática das variáveis socioambientais na busca de dinamização produtiva com perfil endógeno.

Argumenta Sachs (1986) que essas abordagens são consideradas férteis, mas seria preciso levar em consideração as características específicas de cada contexto socioambiental nas análises sobre os sistemas econômicos e, no caso dos APLs, não é diferente. A perspectiva dos arranjos produtivos locais, formulada a partir da realidade brasileira, é uma tentativa de se buscar explicações para problemas socioeconômicos locais no Brasil. Considera-se, por isso, frutífero o estudo sobre essas dinâmicas produtivas, mas é preciso levar em conta que cada região é permeada por sistemas políticos, institucionais e sociais específicos, os quais não podem ser esquecidos. A compreensão da governança local é, portanto, ponto crucial para compreensão 
da dinâmica dos arranjos produtivos locais e o seu impacto sobre meio social e biofísico. Nesse sentido, antes de fazer uma reflexão sobre a necessidade de inserção da dimensão socioambiental nos estudos sobre o desenvolvimento, é necessário levar em conta os avanços recentes sobre a problemática da governança em sua relação com as dinâmicas territoriais de desenvolvimento.

\subsection{Modos de regulação e governança: contribuições para a gestão territorial}

As primeiras acepções do termo governança têm origem na França do século XIII (GAUDIN, 2002). Esse termo apresenta, porém, novos usos no transcurso do século $\mathrm{XX}^{6}$. Além das referências ao domínio público, outros atributos reforçam a sua popularização, como é o caso da microeconomia. No contexto das bases analíticas da microeconomia e na busca de uma definição do conceito de governança, Gaudin (2002) divide-o em dois grandes eixos: um que enfatiza a governança interna das organizações, seus sistemas de gestão e hierarquia e outro que dá ênfase à governança territorial, cuja centralidade recai nos padrões de regulação institucional e de interação existentes no âmbito de um mesmo território.

Na perspectiva territorial, aplicada ao sistema socioeconômico, governança significa um conjunto de sistemas de regulação intencional gerado por uma determinada organização social (BOURQUE, 2000). Para precisar essa definição, Bourque (2000, p. 10) adota o conceito de Hollingsworth e destaca que "[...] um sistema de governança é então definido como a totalidade dos arranjos institucionais que regulam as transações no interior e através das fronteiras de um sistema econômico"7.

Nesse sentido, observa-se que a visão territorial da governança tem uma concepção mais ampla daquela que se tinha no século XIII e XIV e, também, uma concepção oposta à da governança mundial. Nessa perspectiva, ela é mantida por um conjunto de atores e instituições que não pertencem somente à esfera governamental, mas também as relações que se traduzem pela interdependência existente entre o poder e as instituições associadas a uma ação cole- tiva específica. A governança é um processo institucional e organizacional de construção de mecanismos compatíveis com os diferentes modos de coordenação existentes entre atores sociais geograficamente próximos, para que possam resolver os problemas produtivos inéditos, sentidos no território (PECQUEUR, 2004), e para solucionarem problemas que transcendem os limites das relações econômicas.

Para fazer avançar esse debate, Bourque (2000) apresenta, com efeito, uma tipologia dos modos de governança, com o intuito de oferecer outros elementos além daqueles apresentados pelos modos tradicionais de coordenação das atividades econômicas. $\mathrm{O}$ autor supracitado destaca que essa classificação visa ampliar a noção recomendada pelos economistas neoinstitucionalistas, que fundamentam suas análises em duas grandes formas de coordenação econômica: a mercantil e a hierárquica. Essa tipologia mais ampla está escorada em dois postulados. Por um lado, a ação econômica é vista, essencialmente, como uma forma de ação social; por implicação, toda ação social é governada por um conjunto de regras e normas. Por outro lado, constata-se que as atividades econômicas são continuamente influenciadas pelo surgimento de problemas de coordenação. Assim, os modos de governança são definidos como tipos particulares das trocas econômicas socialmente construídas, isto é, trocas que serão estruturadas historicamente pelo processo de organização de papéis definidos no conjunto de relações não econômicas estabelecidas entre os atores. Tais modos de governança asseguram as normas e regras com maior regularidade do que a troca.

De maneira sintética, para Bourque (2000), esses tipos podem ser sintetizados em: i) governança mercantil: conjunto de mecanismos em que os agentes trocam os direitos de propriedade e mecanismos que repousam sobre regras universais: as relações são impessoais, as trocas permutáveis/intercambiáveis e os termos de troca devem satisfazer cada uma das partes; ii) governança hierárquica/corporativa: coordenação exercida por uma autoridade hierárquica fundada sobre os direitos de propriedade, sendo que esses direitos de propriedade são definidos de uma maneira tal que os grandes gestores passam a ser os macroatores tratados como representantes legítimos de múltiplos acionistas; iii) governança estatal: papel de garantir o funcionamento

\footnotetext{
${ }^{6}$ Nos anos de 1990, conforme Gaudin (2002), descobre-se um poder não somente multipolar, complexo, fluido, mas também que é atualmente de alguma forma "descentralizado". O Estado não é mais o centro das coisas; depara-se, na atualidade, com um mundo no qual as instituições se estabelecem por um novo tripé: as relações internacionais, as regulações essenciais e os benefícios dos poderes locais.

${ }^{7}$ Texto original: “ [...] un système de gouvernance est donc defini comme la totalité des arrangements institucionnels [...] qui régulent les transactions à l'intérieur et à travers les frontières d'un système économique.
} 
apropriado dos outros modos de coordenação impostos ao conjunto de atores e das orientações, de acordo com a opinião pública, podendo contar com o potencial da força legítima para produzir bens públicos ou agir diretamente na produção de bens e serviços privados (a diversidade entre os países ou entre os setores econômicos constitui a mais importante fonte de variados sistemas nacionais de governança); iv) governança comunitária: coordenação das atividades ligadas aos indivíduos ou às organizações sobre a base de uma confiança mútua; esta apoia-se sobre relações pautadas em um conjunto de obrigações mútuas e as redes informais não são uma estrutura hierárquica formal e não desembocam sobre uma integração vertical; é um tipo de governança mais flexível que a governança hierárquica e mais estável que a mercantil; e v) governança em parceria/ associativa: contrariamente às redes informais da governança comunitária, as redes da governança associativa são mais formalmente institucionalizadas, constituindo-se no prolongamento formal da governança comunitária; também, por diversas razões (intermediação dos grupos de interesse, forte institucionalização, definição do bem público), a governança associativa é estritamente associada à governança estatal através das diversas formas de delegação de poder.

Assim, tal tipologia apresentada por Bourque (2000) destaca que os modos de governança mercantil, hierárquico, estatal, comunitário e em parceria constituem tipos ideais, que sistematizam os grandes princípios organizacionais mencionados na literatura acadêmica. Na realidade, esses modos de governança se combinam e configuram uma dinâmica de hibridização, em virtude de a realidade ser dinâmica e intercambiante (BOURQUE, 2000; LÉVESQUE, 2001). É preciso, porém, destacar a existência de um amplo espectro de tipos de governança na literatura acadêmica atual. Pesquisadores reconhecidos do tema, como Benko e Lipietz (2000), Courlet e Soulage (1994), e autores como Pecqueur (2006), entre outros, destacaram, no campo socioeconômico, que a governança é entendida como uma forma de organização interempresarial que se caracteriza por relações de poder que vão além do foco do mercado e indicam para a consolidação de formas intermediárias de regulação. Embora essa concepção seja interessante, a de Bourque (2000), cuja sistematização absorveu inúmeras formas possíveis de governança, parece mais coerente para projetos que estejam inseridos em uma perspectiva sistêmica do desenvolvimento e que contemple fortemente a dimensão sociopolítica desse desenvolvimento.

A evolução desse debate reforça a impressão de que a experimentação com novas modalidades de ação coletiva, norteadas pelo ideário do desenvolvimento territorial, vem se intensificando nos últimos tempos. Como parte da ação conjunta, tem-se a consolidação de relações de cooperação, reciprocidade e confiança que são promovidas principalmente pela proximidade geográfica e sociocultural (PECQUEUR, 2005). Num contexto de globalização assimétrica, essas novas modalidades de ação coletiva nos parecem, todavia, ainda fortemente condicionadas pela ideologia economicista, pois colocam em segundo plano o enfrentamento dos dilemas apontados pela visão ecológica dos limites do crescimento material.

Todavia, considera-se fértil a análise pautada nos modos de coordenação setorial, pois esses poderiam refletir-se não somente em termos de organização espacial das atividades econômicas, mas também poderiam ter impacto direto sobre a qualidade territorial, na medida em que os atores sociais sejam mais comprometidos com o território. No caso dos estudos sobre sistemas e arranjos produtivos locais, percebe-se que há uma dinâmica socioeconômica propícia à preocupação com os impactos socioambientais acarretados pelo avanço das atividades econômicas no nível local, especialmente em aglomerações produtivas, cujos modos de regulação se aproximam da governança em parceria (SÁNCHEZ, 1989; 2006). Isso significa dizer que, se as atividades econômicas conseguirem se estruturar privilegiando modos de governança pautados em parcerias, baseados na consertação e na busca por equilíbrio entre as dimensões econômicas, sociais e políticas, menos recorrentes serão os impactos socioambientais graves. Nessa perspectiva, quanto mais distantes estiverem os agentes econômicos, mais próximo eles estarão a um modelo pautado em vantagens comparativas. Isso significa dizer que, quanto mais mecanismos de governança territorial, maiores serão as potencialidades para a construção de modelos de gestão territorial que privilegiem as vantagens diferenciadoras (PECQUEUR, 2006) ${ }^{8}$.

\footnotetext{
${ }^{8}$ A noção de vantagens comparativas remete à perspectiva clássica de David Ricardo, segundo a qual os defensores do livre comércio explicavam que a maior eficiência produtiva, derivada da especialização, contribuiria para a elevação do bem-estar social global. Esse fato ocorreria em função de colocar à disposição dos consumidores maiores volumes de bens e serviços, a preços mais convenientes, sendo que a própria concorrência se encarregaria de regular preço e quantidade de mercadorias a serem vendidas. Já a noção de vantagens diferenciadoras está baseada na premissa de que um sistema produtivo local deveria buscar fugir da concorrência global por meio dos recursos e ativos territoriais específicos. A possibilidade de um território apresentar vantagens diferenciadoras pressupõe a
} 
$\mathrm{Na}$ tentativa de fazer um link entre a abordagem territorial e socioambiental do desenvolvimento, baseado nessa tomada de consciência, justifica-se uma reflexão adicional sobre a temática dos impactos socioambientais dos sistemas produtivos num cenário de fomento de estratégias de desenvolvimento territorial. Como já foi indicado anteriormente, esse esforço de síntese é fruto de uma tentativa de construir um aparato empírico-analítico articulado aos conceitos de APL e governança, sob o pano de fundo da teoria do desenvolvimento territorial sustentável e que pudesse ser replicado por meio dos estudos empíricos nas diferentes regiões do Brasil.

\subsection{Perspectiva de integração da problemática socioambiental no discurso sobre aglomerações industriais}

A problemática socioambiental emergiu no campo do planejamento do desenvolvimento, como já exposto anteriormente, no final dos anos 1960. A discussão sobre o assunto atendeu, inicialmente, aos interesses dos países industrializados. A agenda de prioridades contemplava os problemas da contaminação e degradação ambiental e de um eventual esgotamento dos recursos naturais, agravado pelas evidências de crescimento demográfico exponencial. No transcurso da década seguinte, o foco começou a se deslocar no sentido da incorporação das assimetrias Norte-Sul e do fenômeno da "poluição da pobreza" (SACHS, 2007). Daí em diante, o critério de sustentabilidade ampliada, articulando as dimensões socioeconômica, sociocultural, sociopolítica e socioecológica, vem se impondo como um fator determinante no desenho de estratégias alternativas de desenvolvimento rural e urbano (Quadro 1).

Dentre os primeiros acontecimentos relevantes em âmbito internacional relativos ao debate sobre meio ambiente, tem-se o Relatório de Founex, que apontou os principais tópicos relacionados aos problemas do meio ambiente, rejeitando as abordagens reducionistas do ecologismo "a qualquer preço" e do economicismo estreito (SACHS, 1993). Esses debates foram uma preparação para a Conferência das Nações Unidas que seria realizada, em 1972, em Estocolmo e que buscava, de acordo com
Sachs (1992), uma via intermediária entre as duas visões apontadas anteriormente. Para este autor (1992, p. 7), “[...] a lição mais proveitosa que surgiu de Founex, e depois de Estocolmo, é que seria possível imaginar um caminho de desenvolvimento que fosse ao mesmo tempo socialmente útil, ecologicamente prudente e que atendesse a critérios de eficiência econômica".

Nos anos subsequentes, houve a realização do Seminário do México, em 1974, com preocupações relacionadas ao superdesenvolvimento e subdesenvolvimento na perspectiva do ecodesenvolvimento. Todas essas reflexões culminaram no Relatório Brundtland, em 1987, que levou à convocação da Conferência do Rio de Janeiro, ECO-92, sem contar os eventos paralelos que ocorreram em todo o mundo. As décadas de 1970 e 1980 foram importantes na medida em que conduziram a progressos conceituais, ampliando conhecimento empírico sobre o funcionamento da biosfera, sobre os riscos das atividades humanas, além do avanço na institucionalização da preocupação com o planejamento e a gestão ambiental (SACHS, 1993).

Apesar de ter influenciado um amplo processo de revisão dos fundamentos epistemológicos da ciência econômica, o esforço de pesquisa concentrado, desde o final dos anos 1960, na elucidação do nexo desenvolvimento versus meio ambiente ainda não conseguiu promover uma tomada de consciência efetiva da crise socioambiental e dos seus reflexos no âmbito do mercado. No que diz respeito à problemática deste artigo, as noções de APL e governança territorial muitas vezes são usadas sem uma referência explícita ao conceito sistêmico de sustentabilidade.

Dessa forma, parece importante resgatar a subárea de conhecimento ecológico-humano centrada na avaliação de impactos socioambientais para aprofundar a literatura sobre sustentabilidade. Como referido anteriormente, as diversas conferências sobre o tema desenvolvimento e meio ambiente influenciaram inúmeras áreas de atuação dessa problemática. Dentre elas, verifica-se aquela relativa à avaliação de impacto socioambiental - AIA. Desde a sua origem, no contexto do National Environmental Policy Act (NEPA), em 1969, o significado e o objetivo da avaliação de impacto socioambiental vêm sendo objeto de inúmeras interpretações, dependendo do ponto de vista adotado (SÁNCHEZ, 2006a).

existência de um sistema de governança local, de mecanismos de valorização de identidades culturais e da qualidade do patrimônio natural e cultural. Quanto mais intenso for o sentido de pertencimento ao local, maior se torna a probabilidade de que o território e todos que o compõem - empresas e seres humanos - estejam aquém da expectativa de obtenção de vantagens comparativas, modelo constituído por empresas nômades, no qual buscam a minimização dos custos de produção (PECQUER, 2004, 2006; MENEZES, 2009). 
O debate sobre o conceito de sustentabilidade é antigo. Coube ao cientista alemão Faustmann utilizá-lo pela primeira vez em 1849, visando avaliar economicamente o período de rotação das florestas. Sua utilização recorrente, mas com um perfil reducionista, no campo da gestão de recursos naturais renováveis remonta, contudo, à década de 1930 (HOLLING; BERKES; FOLKE, 1998).

$\mathrm{Na}$ abordagem sistêmica, o termo designa uma grande variedade de objetivos ecológicos (preservação da diversidade genética), sociais (necessidades básicas humanas, mas mantendo os processos ecológicos essenciais e sistemas suporte de vida) e econômicos (assegurar a utilização sustentável das espécies e ecossistemas). Segundo o célebre Relatório Brundtland, o desenvolvimento sustentável seria aquele que atende às necessidades básicas da geração atual sem comprometer o atendimento das gerações futuras.

Os dois tipos de sustentabilidade são contrastantes. O conceito reducionista apreende os recursos como commodities, apontando caminhos para sua eficiente utilização no bojo da teoria econômica neoclássica. O enfoque de gestão de commodities no mercado competitivo e atrelado às expectativas de curto prazo não garante, todavia, a conservação da biodiversidade no longo prazo (HOLLING; BERKES; FOLKE, 1998).

Já, na opinião de Frey (2001), podem ser distinguidas três abordagens desse conceito seminal: (i) a econômicoliberal de mercado, (ii) a ecológico-tecnocrata e (iii) a democrático-participativa. A primeira parte da premissa de que o crescimento econômico conduz automaticamente a um padrão de uso racional dos recursos naturais, ao progresso técnico e à abertura de novas necessidades de consumo compatíveis com a conservação do meio ambiente. A segunda vertente orienta-se no sentido de reconhecer a intervenção estatal como uma condição necessária, através do planejamento, para se evitar os impactos socioambientais destrutivos das dinâmicas de crescimento econômico. Por sua vez, a terceira perspectiva "almeja antes de tudo a defesa da humanidade ou uma vida digna para todos; em consequência, deveria propiciar também relações cada vez mais harmoniosas com a natureza" (FREY, 2001, p. 22).

Outra linha de argumentação relevante apoia-se na contribuição clássica de Ignacy Sachs, um dos arquitetos do enfoque de ecodesenvolvimento (1993). Ele distingue cinco dimensões do conceito: i) sustentabilidade social, relacionada à construção de uma nova civilização do ser, em contraposição à civilização do ter; ii) sustentabilidade econômica, "possibilitada por uma alocação e gestão mais eficientes dos recursos e por um fluxo regular do investimento público e privado. [...] a eficiência econômica deve ser avaliada mais em termos macrossociais do que apenas por meio de critérios de lucratividade microempresarial"; iii) sustentabilidade ecológica, a ser alcançada por meio da engenhosidade na utilização da base de recursos potenciais existente nos diversos ecossistemas, da limitação do consumo de recursos não renováveis e produtos facilmente esgotáveis e sua substituição por recursos renováveis; redução da poluição mediante a reciclagem sistemática de dejetos das atividades produtivas e de consumo; combate ao consumo supérfluo de mercadorias; pesquisa de tecnologias limpas e, por fim, definir regras para proteção ambiental, bem como dispor de um aparato institucional que assegure o cumprimento das normas propostas; iv) sustentabilidade espacial, no sentido do aperfeiçoamento progressivo das configurações rural-urbanas; e, finalmente, v) sustentabilidade cultural, relacionada à "[...] busca das raízes endógenas dos modelos de modernização e dos sistemas rurais integrados de produção, privilegiando processos de mudança no seio da continuidade cultural e traduzindo o conceito normativo de ecodesenvolvimento em uma pluralidade de soluções particulares, que respeitam as especificidades de cada ecossistema, de cada cultura e de cada local" (SACHS, 1993, p. 27).O debate sobre o conceito de sustentabilidade é antigo. Coube ao cientista alemão Faustmann utilizá-lo pela primeira vez em 1849, visando avaliar economicamente o período de rotação das florestas. Sua utilização recorrente, mas com um perfil reducionista, no campo da gestão de recursos naturais renováveis remonta, contudo, à década de 1930 (HOLLING; BERKES; FOLKE, 1998).

FONTES: Holling, Berkes e Folke (1998); Frey (2001); Sachs (1993). 
Trata-se de uma técnica concebida para identificar, prever, interpretar e comunicar por meio de informações precisas os impactos de uma dada ação sobre a saúde e bem-estar humanos, bem como sobre a conservação da funcionalidade dos sistemas de suporte da vida. É preciso destacar que a avaliação de impacto ambiental não é apenas concebida para avaliar o dano de maneira estanque, mas os possíveis danos presentes e futuros. Além disso, no âmbito operacional dessa ferramenta de gestão ambiental, reconhece-se que a AIA pode desempenhar quatro papéis: i) planejamento de projeto: avaliação dos possíveis impactos ambientais para a implantação de empreendimentos produtivos (em todas as suas fases: planejamento, implantação, operação, desativação); ii) auxílio à tomada de decisão: visibilidade dos possíveis impactos das ações produtivas sobre o meio ambiente e possíveis reversões do quadro de degradação; iii) promoção da participação pública: administração dos conflitos oriundos das divergências de interesses entre os agentes sociais envolvidos no processo da AIA, geralmente colocado em prática pelas "audiências públicas"; iv) gestão ambiental: monitoramento do impacto das ações produtivas sobre o meio natural e social, ou seja, práticas empresariais adotadas que minimizam os efeitos nocivos ao ambiente causados por suas atividades (SÁNCHEZ, 1995, 2006a, 2006b; ASBY, 1995; CONAMA, 2007).

Do conjunto dessas funções, aquela relativa ao planejamento e à gestão ambiental é considerada, ainda hoje, como a menos explorada no esforço de pesquisa aplicada. A função precípua da AIA seria incitar os empreendedores a conceberem projetos ambientalmente menos agressivos e não simplesmente julgar se os impactos são aceitáveis ou não. A gestão ambiental, nesse contexto, deverá ser apreciada de forma sistêmica. Além disso, a sua internalização parece estar ocorrendo, na visão de Oliveira e Machado (2010), de forma gradativa. Vale lembrar, entretanto, que é mister no contexto ecológico atual que as empresas estejam preparadas para as novas formas de gestão, bem como aos novos requisitos de relevância e atuação social. As organizações produtivas territorializadas, como é o caso dos APLs, parecem estar preocupadas com o local, destacando que o local implica os atores sociais, a cultura e o meio ambiente. E, nesse sentido, poderiam iniciar um processo de mudança no paradigma de gestão atual.

Reconhecendo que existem inúmeros programas governamentais que apoiam a consolidação do instrumento da AIA no Brasil, percebe-se que a gestão pública deverá sair do plano do planejamento e da normatização para o plano da ação. Considera-se relevante o trabalho de nor- matização existente no Brasil, como é o caso da resolução do CONAMA 01/86, que define impacto ambiental como:

[...] qualquer alteração das propriedades físicas, químicas e biológicas do meio ambiente causada por qualquer forma de matéria ou energia resultante das atividades humanas que direta ou indiretamente, afetam: I - a saúde, a segurança e o bem-estar da população; II - as atividades sociais e econômicas; III - a biota; IV - as condições estéticas e sanitárias do meio ambiente; $\mathrm{e} \mathrm{V-a}$ qualidade dos recursos ambientais (CONAMA, 2007).

Nota-se, porém, que são ainda precários os dados disponíveis sobre impactos socioambientais setoriais de projetos, programas e políticas de desenvolvimento rural e urbano. De um lado, as empresas não se engajam de maneira efetiva e, de outro lado, o poder público também o faz de forma superficial. Por isso, a ferramenta da AIA pode ser um instrumento eficaz na geração de elementos relevantes para dar subsídios à tomada de decisão, tanto pública quanto privada.

Considera-se imprescindível o encaminhamento de estudos técnicos sobre o tema para se pensar uma forma de auxiliar na tomada de decisão sobre a implantação de atividades consideradas potencialmente predatórias, principalmente no âmbito de setores concentrados territorialmente e sobre as políticas de fomento orientadas pela gestão pública. Visto que quando um território apresenta aglomerações industriais, pressupõe-se o aumento do consumo do recurso hídrico, da energia elétrica e mesmo da geração de dejetos em âmbito local, assim como o aumento do número de empregos e de possibilidades de produção e consumo. Cabe saber qual é o equilíbrio desses elementos e qual é a capacidade de suporte dos meios social e biofísico terrritorial para que se façam as escolhas mais acertadas.

Dessa forma, observa-se que não existem somente impactos no meio biofísico, mas também eles podem ser seguidos por impactos no meio social. Então, considera-se que a discussão sobre impactos sociais das atividades produtivas merecem, também, algumas observações cursivas. Na opinião de Vanclay (2003), a Avaliação de Impactos Sociais - AIS - caracteriza uma proposta de avaliação de impactos sociais de intervenções ou eventos planejados e de concepção de estratégias para o monitoramento e gerenciamento em curso desses impactos. Ela não deve, portanto, ser entendida somente como parte de um esforço de previsão dos impactos sociais num processo de avaliação de impacto ambiental (VANCLAY, 2003). Trata-se, antes, de uma estrutura em arco que incorpora a avaliação do conjunto de impactos 
sobre os seres humanos e sobre os modos de interação de pessoas e comunidades com seu entorno - sejam eles socioculturais, socioeconômicos ou biofísicos. No rol dos itens passíveis de avaliação estão incluídos: o modo de vida das pessoas; a cultura; a comunidade; os sistemas políticos; o meio ambiente; a saúde e o bem-estar; os direitos pessoais e de propriedade; os medos e as aspirações.

A linha de argumentação até o momento destaca, assim, a importância de serem avaliados os custos sociais e ecológicos das atividades produtivas, como bem alertava Kapp (1976). Acredita-se, por isso, que a noção de perda também deveria ser resgatada. Esse conceito tem sido enfatizado por um campo da economia que surgiu no final da década de 1980, nos Estados Unidos: a economia ecológica. Essa corrente emerge como contraponto à utilização dos modelos da economia neoclássica ${ }^{9}$ e da ecologia convencional ${ }^{10}$ que demonstraram ser insuficientes na compreensão dos problemas ecológicos globais (MAIMON, 1992).

As discussões desse novo campo da economia contribuíram, também, para se pensar inovações no conceito de desenvolvimento. Toda a discussão teórica sobre economia ecológica, embora com orientações teórico-metodológicas diversas, tem buscado colocar em evidência os problemas da economia em compreender as dinâmicas produtivas inseridas nos ecossistemas. É preciso, portanto, integrar o elemento da gestão dos resíduos industriais ao debate levantado pela economia ecológica, já que a sua boa gestão poderia acarretar a minimização das perdas. As técnicas de ecoeficiência poderiam ser incorporadas às análises atuais sobre sistema produtivo e meio ambiente. Com elas as organizações poderão aliar a redução do uso dos recursos naturais, como energia, matérias, água e solo e a redução do impacto na natureza, como a diminuição na poluição do ar e da água, com o aumento da produtividade ou no valor do produto/serviço (MUNK; DIAS; SOUZA, 2010).

Sachs (1986) destacou que a perda deveria ser um termo banido do vocabulário dos agentes de desenvolvimento, uma vez que ela poderia deixar de ser um custo (social ou individual) para se tornar recurso com valor de troca potencial, realimentando os sistemas produtivos, se ela puder ser reutilizada. Dessa forma, as perdas, que geralmente representam custos sociais, poderiam ser sistematicamente reintegradas aos sistemas produtivos na forma de insumos (KAPP, 1976). No caso dos APLs, haveria potencialmente a possibilidade de integração e o surgimento de mais atividades produtivas para reaproveitamento dos dejetos e resíduos.

Situa-se, então, que a problemática socioambiental está no seio de uma discussão mais ampla sobre os rumos do desenvolvimento. Além disso, destaca-se o fato de que se está diante de uma crise ecológica iminente que, segundo Jackson (2011), terá um impacto mais violento sobre os preços do que a crise financeira de 2008. A capacidade de o planeta assimilar os impactos ambientais da atividade econômica parece estar no centro dessa crise. Observa-se, por isso, que todos os mecanismos de redução de perdas, de reaproveitamento em sistemas produtivos integrados poderão gerar uma alternativa viável ambientalmente para todo o sistema econômico. Considera-se, portanto, que os APLs são estruturas produtivas mais propícias a tais adaptações.

Essas contribuições são importantes para o planejamento do desenvolvimento territorial sustentável na medida em que se torna essencial elucidar, de forma criteriosa, a complexidade embutida no funcionamento da economia real (Ignacy Sachs); ou seja, compreender, cada vez melhor, como as pessoas se relacionam cotidianamente para assegurar a consistência de suas estratégias de sobrevivência e para o exercício da autonomia (self-reliance ${ }^{11}$ ). A introdução de uma perspectiva integradora entre meio ambiente e sociedade busca traduzir que o homem, isolado no contexto do mercado, parece dono de seu destino, tentando modelar e governar a natureza. Cabe lembrar que, conforme Passet (1979), o homem está na natureza, a natureza está no homem; o homem é, portanto, a natureza ${ }^{12}$. Reconhecendo tal premissa e tendo a capacidade de prever as consequências

\footnotetext{
9 “A economia neoclássica, versão moderna e mais estreita da teoria clássica, acredita que o livre jogo das forças de mercado, em situação de livre competição (o que significa perfeita informação dos agentes econômicos), será capaz de promover a mais eficiente alocação de recursos, a mais elevada produção, a mais justa distribuição da renda, o mais rápido progresso tecnológico, a mais apropriada utilização da natureza" (CAVALCANTI, 2004, p. 150).

${ }^{10}$ A ecologia convencional é evolucionista e atomística. Sem contar que, nessa perspectiva, a hipótese central é de que a evolução atuando no nível genético é vista como dominante, pois a base dos recursos é limitada e a espécie humana é, como outra qualquer espécie, raramente estudada. Os objetivos, no contexto da ecologia convencional, são os da sobrevivência das espécies.

${ }^{11}$ Esse termo, segundo Galtung (1977), tem sua origem na China, citado pela primeira vez, em 1945, por Mao Tse-tung. Dentro da perspectiva de Mao Tse-tung, entende-se esse termo como "regeneração através dos nossos próprios esforços".

${ }^{12}$ Isolé dans le marché, apparemment maître de son destin, l'Homme pouvait apparaître comme un être à part, gouvernant et modelant la Nature, en quelque sorte de l'extérieur. Mais cette attitude anthropocentrique se heurte à tout ce que nous savons de l'évolution. En fait: - l'Homme est dans la Nature [...] - la Nature est dans l'Homme [...] - l'Homme, enfin, est la Nature [...] Le problème qui se pose est celui d'une espèce dominante qui, en raison même de sa dominance, compromet la reproduction du milieu qui la porte et dont la plasticité n'est pas infinie; mais pour la première fois certainement dans le cours de l'évolution, d'une espèce consciente qui possède la faculté de penser sa position et de prévoir les conséquences de ses actes au sein de ce milieu (PASSET, 1979).
} 
das atividades humanas, o homem poderá reverter o quadro de degradação da sua própria existência. As bases do DTS estão pautadas nessa premissa de que o desenvolvimento deve contemplar todas as necessidades de manutenção da vida humana; isso inclui, pois, a de manutenção dos meios social, cultural, político e, obviamente, a manutenção do meio biofísico.

\section{Considerações finais}

O interesse crescente, especialmente nas décadas de 1970 e 1980, pela compreensão da dinâmica de funcionamento dos sistemas produtivos em âmbito local esteve atrelado a inúmeras mudanças surgidas no ambiente econômico globalizado. Essas transformações apontam no sentido da superação do modelo fordista, mediante novas formas de organização industrial. As aglomerações industriais são essas novas formas de organização produtiva que tendem a combinar aspectos do mercado à reciprocidade, dando lugar a uma prática, a uma realidade territorial, na qual o componente identitário se destaca, colocando em xeque um dos princípios básicos da economia política clássica: a separação entre o econômico e o social.

Não se pode, entretanto, menosprezar o peso das controvérsias científicas suscitadas pelos estudos sobre as experiências da Terza Itália, exemplo exitoso desse tipo de dinâmica produtiva. Observa-se que, de acordo com Veiga (2006), as discussões sobre essa dinâmica produtiva local não chegaram a evidenciar, necessariamente, as razões da existência de maior ou menor dinamismo econômico em territórios específicos. Além disso, a experiência italiana está inserida numa dinâmica que, em alguns casos, não poderá ser extrapolada para todas as localidades ou países do mundo. No caso italiano, verifica-se “[...] uma fortíssima correlação entre a distribuição espacial da economia 'difusa', que caracterizava suas províncias mais dinâmicas, e a intensidade das formas familiares de agricultura" (VEIGA, 2006, p. 9). Obviamente, constata-se aqui a presença de componentes específicos de uma organização municipal da região Centro-Norte italiana, a qual tem origem na Idade Média, com importante divisão territorial do trabalho entre cidade e campo, acabando por propiciar um ambiente favorável a esse tipo de dinâmica territorial (PUTNAM, 2002).

Apesar de seus limites, a experiência italiana pode ser tomada como exemplo de uma estratégia exitosa de industrialização descentralizada e endógena. Essa experi- ência resgata aspectos importantes da vida econômica em "sociedade" (CARRIÈRE; CAZELLA, 2006). Assim, os modos de regulação e governança são elementos-chave para se pensar esse tipo de organização territorial, que ultrapassa os limites da simples organização econômica do território. São esses modos de governança que constituem canais propícios à formação de uma consciência ecossocioeconômica que poderia alavancar estratégias de desenvolvimento territorial sustentável.

Seguindo a tendência da dinâmica produtiva local italiana e reconhecendo as especificidades da realidade brasileira, é importante, conforme exposto nas seções anteriores, resgatar as contribuições dos estudos e pesquisas sobre arranjo produtivo local para se pensar estratégias de desenvolvimento mais ajustadas no âmbito territorial. Além disso, para que a governança rumo ao desenvolvimento territorial sustentável seja integrada e fortalecida, a introdução e a avaliação da questão socioambiental são caracterizadas como condição sine qua non, uma vez que a qualidade do meio ambiente representa um elemento essencial para a promoção da "qualidade territorial" (CRUZ FILHO, 2006; LÉVESQUE, 2001; BOURQUE, 2000; CUNHA, 2007; LE GALÈS, 2004, GAUDIN, 2002). Fazer avançar o debate sobre os APLs e a governança implica destacar a importância dos diferentes atores na negociação dos rumos sobre o sistema econômico e seus impactos sobre o território.

No que se refere aos elementos sobre avaliação de impacto socioambiental e a discussão sobre sustentabilidade, é fato que sejam elementos imprescindíveis para a compreensão dos limites da evolução das atividades produtivas no âmbito territorial. É relevante salientar que as aglomerações produtivas revelam impactos, às vezes perversos, aos territórios. Embora se saiba que as externalidades positivas, já destacadas por Marshall, sejam bastante evidentes, as externalidades negativas foram, ainda, pouco estudadas pelos pequisadores da economia, geografia e de outras áreas afins. Em inúmeros estudos, verifica-se que a concentração industrial requer do território uma infraestrutura elétrica e de distribuição de água crescente. A partir dessas constatações, afirma-se que tais necessidades demonstram impactos sobre o meio biofísico e, consequentemente, social.

Considera-se, assim, que a ferramenta da AIA pode ser um mecanismo ajustado à dinâmica de organizações industriais concentradas conduzidas no âmbito "territorial", principalmente por aqueles setores com forte potencial de degradação (social, econômica e biofísica), visando reorientar as ações produtivas locais a partir do reconheci- 
mento de riscos socioambientais. Além disso, a evolução das atividades, numa dada aglomeração industrial, deveria ser orientada por estudos com periodicidade anual, visando avaliar a compatibilização das atividades produtivas e seus incrementos anuais no nível territorial. Destaca-se que a partir do aumento da produtividade das empresas e do surgimento de novas empresas, a jusante e a montante da filière (cadeia produtiva), percebe-se a elevação do nível de consumo energético, a necessidade de tratamento e adequação do destino dos resíduos, a emissão de gases geradores do efeito estufa, os riscos de deterioração da qualidade dos solos agricultáveis etc.

Todas essas questões suscitaram um esforço acadêmico no sentido de promover pesquisas que incorporassem as questões territoriais e socioambientais do desenvolvimento. Entretanto, tais estudos ainda têm refletido a predominância das questões socioeconômicas em detrimento das socioambientais, como comprovado pelos trabalhos realizados por pesquisadores que estudaram a realidade catarinense, empreendidos mediante uma parceria entre a Universidade Federal de Santa Catarina - Santa Catarina, a Universidade Federal de Campina Grande - Paraíba e a Universidade de Tours - na França. Tais pesquisadores compartilharam essa problemática, culminando em estudos como o da aglomeração industrial têxtil-vestuarista do Alto Vale do Itajaí, de Menezes (2009), o da dinâmica de planejamento, empreendido por Butzke (2007), e o da pesquisa sobre organizações de produtores agroecológicos, realizada por Andion (2007), entre outros.

\section{Referências}

AMARAL FILHO, Jair. A endogeneização no desenvolvimento econômico regional e local. Disponível em: $<$ http://www.ipea. gov.br/pub/ppp/ppp23/Parte7.pdf > . Acesso em: fev. 2007.

ANDION, Maria Carolina. Atuação das ONGs nas dinâmicas de desenvolvimento territorial sustentável no meio rural de Santa Catarina: os casos da APACO, do Centro Vianei de Educação Popular e da Agreco. Florianópolis, 2007. 385 f. Tese (Doutorado) - Programa Interdisciplinar em Ciências Humanas, UFSC. Florianópolis, 2007.

ARRIGHI, Giovanni. A ilusão do desenvolvimento. Petrópolis: Vozes, 1998.
Por fim, foi proposta neste artigo uma reflexão em que se buscou frisar a relevância da abordagem do desenvolvimento territorial sustentável, que alia a questão territorial à socioambiental, num período de grandes transformações e discussão sobre os rumos da dinâmica capitalista. Embora a literatura sobre a abordagem do desenvolvimento territorial e do ecodesenvolvimento seja já bastante densa e vasta, esse ensaio teórico teve o fim de recordar a relevância da integração dessas abordagens que, de maneira inventiva, poderia dar subsídios para o avanço teórico sobre o binômio desenvolvimento e meio ambiente.

Conclui-se, por meio desse ensaio, que o resgate dessa literatura requer uma mudança paradigmática dos pesquisadores do campo da economia, sociologia, geografia, ecologia, entre outros, no sentido de constituírem estudos empíricos, principalmente acerca do impacto das aglomerações industriais sobre os meios social e ecológico, bem como poderiam influenciar na tomada de decisão de políticas públicas orientadas para esse tipo de organização produtiva. Além disso, a partir desses estudos, seriam detalhados os avanços e limites dessas estruturas produtivas na minimização dos impactos perversos. E, por fim, através da identificação dos avanços e limites recorrentes desse tipo de dinâmica produtiva sobre o meio ambiente e sobre a sociedade, num esforço de integrar as questões de cunho global às de cunho local, poder-se-ia fazer avançar esse novo enfoque de planejamento e gestão: o desenvolvimento territorial sustentável.
ASBY, Miriam Laila et. al. Avaliação de impacto ambiental: agentes, procedimentos e ferramentas. Brasília: Instituto do Meio Ambiente e dos Recursos Renováveis, 1995.

BAGNASCO, Arnaldo. Desenvolvimento regional, sociedade local e economia difusa. In: COCCO, Giuseppe; URANI, André; GALVÃO, Alexandre Patez. Empresários e empregos nos novos territórios produtivos: o caso da terceira Itália. Rio de Janeiro: DP\&A, 1999.

BECATTINI, Giácomo. Les districts industriels. In: MARUANI, M. et. al. La flexibilité en Italie. Paris: MIRE, Syros/ Alternative, 1989. 
Os distritos industriais na Itália. In: $\mathrm{COCCO}$, Giuseppe; URANI, André; GALVÃO, Alexandre Patez. Empresários e empregos nos novos territórios produtivos: o caso da terceira Itália. Rio de Janeiro: DP\&A, 1999.

BENKO, Georges. Economia espaço e globalização: na aurora do século XXI. São Paulo: Hucitec, 1996.

; LIPIETZ, Alain. La richesse des régions: la nouvelle géographie socio-économique. Paris: Économie en Liberté, 2000.

BOURQUE, Gilles L. De l'ancienne à la nouvelle économie: un processus de modernisation sociale de l'industrie. Cahiers $d u$ CRISES.. Mars 2000. (Coleção Working Papers, n. ET0006.)

BUTZKE, Luciana. O papel das associações de municípios na dinâmica de planejamento regional e urbano em Santa Catarina: estudo de caso sobre a trajetória da Associação dos Municípios do Alto Vale do Itajaí. 2007. 142f. (Dissertação de Mestrado, Programa de Pós-graduação em Sociologia Política), UFSC. Florianópolis, 2007.

CARRIÈRE, Jean-Paul; CAZELLA, Ademir Antônio. Abordagem introdutória ao conceito de desenvolvimento territorial. Eisforia - desenvolvimento territorial sustentável: conceitos, experiências e desafios teórico-metodológicos. Florianópolis, v. 4, n. especial, dez. 2006.

CAVALCANTI, Clóvis. Uma tentativa de caracterização da economia ecológica. Ambiente \& Sociedade, v. 7, n. 1, jan./ jun. 2004

CAZELLA, Ademir Antônio. Contribuições metodológicas da socioantropologia para o desenvolvimento territorial sustentável. Eisforia - desenvolvimento territorial sustentável: conceitos, experiências e desafios teórico-metodológicos, Florianópolis, v. 4, n. especial, dez. 2006.

COCCO, Giuseppe; GALVÃO, Alexandre Patez; SILVA, Mirela Carvalho Pereira. Desenvolvimento local e espaço público na terceira Itália: questões para a realidade brasileira. In: COCCO, Giuseppe; URANI, André; GALVÃO, Alexandre Patez. Empresários e empregos nos novos territórios produtivos: o caso da terceira Itália. Rio de Janeiro: DP\&A, 1999.

CONAMA. Resolução 01/1986. Disponível em: <http://www. $\mathrm{mma}$. gov.br/port/conama/legiabre.cfm? codlegi $=23>$. Acesso em: 05/2007.

COURLET, Claude; SOULAGE, Bernard. Industrie, territoires et politiques publiques. Paris: L'Harmattan, 1994.

Territoires et régions, les grands oubliés du developpement économique. Paris: L'Harmattan, 2001.
CRUZ FILHO, Paulo Roberto Araújo. Governança e gestão de redes na esfera pública municipal: o caso da rede de proteção à criança e ao adolescente em situação de risco para a violência em Curitiba. Curitiba, 2006. 150 f. Dissertação (Mestrado em Administração) - Programa de Pós-Graduação em Administração. Pontifícia Universidade Católica do Paraná, 2006.

CUNHA, Idaulo José. Governança, internacionalização e competitividade: de aglomerados produtivos de móveis no Sul do Brasil, Portugal e Espanha. Chapecó: Arcus Indústria Gráfica, 2007. p. 394.

FREY, Klaus. A dimensão político-democrática das teorias de desenvolvimento sustentável e suas implicações para a gestão local. Ambiente e Sociedade, Campinas, v. 4, n. 9, p. 115-148, set. 2001.

GAUDIN, Jean-Pierre. Pourquoi la gouvernance? Paris: Presses de Sciences Po, 2002.

HOLLING, C. S.; BERKES, F.; FOLKE, C. Science, sustainability and resource management. In: BERKES, F.; FOLKE, C.; COLDING, J. (Orgs.). Linking social and ecological sistems: management practices and social mechanisms for building resilience. Cambridge: Cambridge University Press, 1998. p. 342-362.

JACKSON, Tim. Prospérité sans croissance: la transition vers une écnomie durable. Paris: De Boeck, 2011.

KAPP, Karl William. Les coûts sociaux dans l'economie de marché. Paris: Flammarion, 1976.

LASTRES, Helena M. M.; CASSIOLATO, José Eduardo. Sistemas de inovação e arranjos produtivos locais: novas estratégias para promover a geração, aquisição e difusão de conhecimento. Revista Centro de Ciências Administrativas, Fortaleza, v. 9, n. 2, p. 189-195, dez. 2003.

LE GALÈS, P. À chaque ville sa gouvernance. Hors-série, Auxerre: Sciences Humaines, n. 44, 2004.

LEMOS, Cristina. Micro, pequenas e médias empresas no Brasil: novos requerimentos de políticas para a promoção de sistemas produtivos locais. 2003. 269 f. Tese (Doutorado em Engenharia de Produção) - Programa de Pós-Graduação em Engenharia de Produção, Universidade Federal do Rio de Janeiro. Rio de Janeiro, 2003.

LÉVESQUE, Benoît. Le partenariat: une tendance lourde de la nouvelle gouvernance à l'ère de la mondialisation. Enjeux et défis pour les entreprises publiques et d'économie sociale. Cahiers du CRISES, Avril, 2001. 
MAILLAT, Denis. Milieux innovateurs et dinamique territoriale. In: RALET, A.; TORRE, A. (Hrsg.). Economie industrielle et economie spaciale. Paris: Economica, 1995. p. 211-232.

MAIMON, Dália. Ensaios sobre economia do meio ambiente. Rio de Janeiro: APED, 1992.

MARSHALL, Alfred. Princípios de economia. São Paulo: Nova Cultural, 1982.

MEADOWS, Donella et al. Limites do crescimento. São Paulo: Perspectiva, 1978.

MENEZES, Elaine Cristina de Oliveira. Industrialização e meio ambiente no Estado de Santa Catarina: estudo de caso sobre a evolução e os impactos socioambientais do segmento têxtil-vestuarista na microrregião do Alto Vale do Itajaí. 2009. 317 f. Tese (Doutorado em Sociologia Política) - Programa de Pós-graduação em Sociologia Política, Universidade Federal de Santa Catarina. Florianópolis, 2009.

MUNK, Luciano; DIAS, Bárbara Galleli; SOUZA, Rafael Borim de. Sustentabilidade organizacional: uma análise a partir da institucionalização de práticas ecoeficietntes. In: Anais SIMPOI FGV, 2010. Disponível em: <http://www.simpoi. fgvsp.br/arquivo/2010/artigos/E2010_T00183_PCN58078. pdf $>$. Acesso em: 26/07/2011.

OLIVEIRA, Ricardo Luciano de; MACHADO, André Gustavo Carvalho. Gestão ambiental empresarial: estudo de casos em empresas líderes dos setores supermercadistas e de refrigerantes. In: Revista de Gestão Social e Ambiental, v. 4, n. 2, maio/ago. 2010.

PASSET, René. L'économique et le vivant. Paris: Payot, 1979.

PECQUEUR, Bernard. Le développement territorial: une nouvelle approche des processus de développemente pour les economies du Sud. France: s.n., 2004. (mimeo)

A guinada territorial da economia global. Florianópolis: s.n., 2005. (Palestra proferida junto ao Curso de Graduação e Programa de Pós-Graduação em Agronomia, CCA - UFSC). Florianópolis, 2005.

. A guinada territorial da economia global. Eisforia desenvolvimento territorial sustentável: conceitos, experiências e desafios teórico-metodológicos. Florianópolis: PPGAGR, v. 4, n. especial, dez. 2006.

PIORE, Michael J.; SABEL, Charles F. The second industrial divide: possibilities for prosperity. New York: Basic Books, 1984.
PORTER, Michael. Aglomerados e competição: novas agendas para empresas, governos e instituições. In: Competição. Rio de Janeiro: Campus, 1999.

PUTNAM, Robert D. Comunidade e democracia: a experiência da Itália moderna. 3 ed. Rio de Janeiro: Editora FGV, 2002.

REDESIST. Disponível em: <http://www.redesist.ie.ufrj.br>. Acesso em: 30/04/2007.

ROSENFELD, S. A. États-Unis: Les agglomerations d'entreprises. In: OCDE. Réseaux d'entreprises et développement local (ou Network et de Développement). Paris: Ed. Organisation de Coopération et de Dévelopement Économique, 1996.

SACHS, Ignacy. Ecodesenvolvimento: crescer sem destruir. São Paulo: Vértice, 1986.

. Ecodesenvolvimento: 1972-1992. Agricultura e Meio Ambiente, Rio de Janeiro: Universidade Federal do Rio de Janeiro, ano 1, n. 1, 1992.

Estratégias de transição para o século XXI: desenvolvimento e meio ambiente. São Paulo: Studio Nobel; FUNDAP, 1993.

Rumo à ecossocioeconomia: teoria e prática do desenvolvimento. São Paulo: Cortez, 2007.

SÁNCHEZ, Luis Enrique. Les roles des études d'impact des projets miniers. 1989. 305 f. Tese (Doutorado em Economia dos recursos naturais e desenvolvimento) - L'École National Superieur des Mines de Paris.

. Avaliação de impacto ambiental: conceitos e métodos. São Paulo: Oficina de textos, 2006a.

Avaliação de impacto ambiental e seu papel na gestão de empreendimentos. In: VILELA JUNIOR, Alcir; DEMAJOROVIC, Jacques. Modelos e ferramentas de gestão ambiental: desafios e perspectivas para as organizações. São Paulo: Editora Senac, 2006b.

SCHUMPETER, J. The theory of economic development. Cambridge: Harvard University, 1934.

VANCLAY, Frank. International principles for social impact assessment. Impact assessment and project appraisal, v. 21, n. 1, mar. 2003.

VEIGA, José Eli da. Empreendedorismo no Brasil. Disponível em: <www.econ.fea.usp.br/zeeli/Textos/ultimos_trabalhos>. Acesso em: jan. 2006. (Relatório de pesquisa)

VIEIRA, Paulo Freire. Gestão de recursos comuns para o ecodesenvolvimento. In: ; BERKES, Fikret; SEIXAS, 
MENEZES, E. C. O.; VIEIRA, P. H. F. Aglomeração industrial, governança e meio ambiente: conceitos...

Cristiana S. (Orgs.). Gestão integrada e participativa de recursos naturais. Florianópolis: Secco; APED, 2005.

Rumo ao desenvolvimento territorial sustentável: esboço de roteiro metodológico participativo. Eisforia - desenvolvimento territorial sustentável: conceitos, experiências e desafios teórico-metodológicos, Florianópolis, v. 4, n. especial, dez. 2006.

; CAZELlA, Ademir Antônio (Org.). Desenvolvimento territorial sustentável: diagnóstico de potencialidades e obstáculos em zonas rurais dos Estados da Paraíba e Santa Catarina. Florianópolis: s.n., 2004. (Modelo de análise referente ao projeto de pesquisa - mimeo)

; CUNHA, Idaulo José. Repensando o desenvolvimento catarinense. In: (Org.). A pequena produção e o modelo catarinense de desenvolvimento. Florianópolis: APED, 2002.

WALLERSTEIN, Immanuel. Após o liberalismo: em busca da reconstrução do mundo. Petrópolis: Vozes, 2002.

Recebido em agosto de 2011.

Aceito em outubro de 2011.

Publicado em dezembro de 2011. 